\title{
Southern Med Review: A New Forum to Publish "Local Pharmaceutical Policy in a Global Context"
}

\author{
Zaheer-Ud-Din Babar · Terri-Louise Beswick
}

Published online: 3 March 2009

(C) Springer Science+Business Media B.V. 2009

Dear reader,

Pharmacy World \& Science is doing very well. In 2008 we received 234 submissions from 52 countries, but the rejection rate also went up to $66 \%$. This was not only due to quality issues: half of the rejected papers were simply not within the scope of the journal. Often these were good papers coming from South/East Asia, describing prescribing practices in that region. But because PWS is a European journal, we would only publish such papers if they can be placed in a truly international context.

But times are changing, as you can see from the editorial below. New journals are being created, and although they do not have an impact factor yet, this would be a new journal that I would recommend for epidemiological papers on prescribing in that region.

I do wish our colleagues much success.

Foppe van Mil, $\mathrm{PhD}$

Editor-in-chief PWS

\section{Southern Med Review}

Appropriate research into pharmaceutical policy can produce real benefits for both the use of medicines and resource allocation for medicines. However, publishing the research

Zaheer-Ud-Din Babar: Editor of Southern Med Review.

Z.-U.-D. Babar $(\bowtie)$

School of Pharmacy, University of Auckland,

Auckland, New Zealand

e-mail: z.babar@auckland.ac.nz

T.-L. Beswick

Health Action International Global (HAI),

Amsterdam, The Netherlands in an appropriate and high impact forum is a crucial component for initiating policy benefits. It not only informs the readership about the research process, but it also has a significant impact on public health and nurtures further inquiry.

At a pharmaceutical policy conference in 2007, organized by the World Health Organization and the Utrecht Institute of Pharmaceutical Sciences, one of the main themes was "how to foster pharmaceutical policy publishing in high impact journals." This choice of topic demonstrates the continuing challenges facing pharmaceutical policy research in the global arena. In developing countries, the challenge of publishing is even greater because of inexperienced researchers and regionally-specific topics that do not fit within the scope of mainstream journals. This publishing 'gap' is especially harmful in the 'Global South' where the need to publish policy research is far greater because health systems are generally weaker and health policy is still evolving.

Where the need for publishing pharmaceutical policy papers is clear, there is a lack of platforms for publication. It is especially hard to find a 'home' for research papers focusing on the pharmaceutical policy of developing countries. Many mainstream health policy journals have published studies on developing countries, although a large number of these studies are published in concert with western counterparts. Contemporary pharmacy practice journals have also provided opportunities to researchers from the south, but naturally these journals are housed in the western context and studies with a more local content are often rejected.

Several studies published in the top pharmacy practice journals emphasize "pure methodological aspects" or "advanced pharmacy services", which are not so pertinent to contemporary pharmaceutical policy in developing countries. The obstacles for publishing pharmaceutical 
policy research by and for developing countries are a clear signal that developing countries need an innovative, sensitized and culturally relevant platform on which to showcase their own issues. The new journal, Southern Med Review aims to fulfill this role by encouraging scholarly discourse and the dissemination of knowledge within a local health policy context. We intend to strengthen the evidence base for fundamental issues such as, medicines' access and affordability; the importance of medicine and pharmacy education within health systems; strengthening the pharmaceutical system, pharmacoepidemiology and socio-behavioral aspects of medicine use.

For emerging researchers, the journal will offer a supportive environment and 'author friendly' policies while maintaining a high quality peer review process. There will also be opportunities for established research leaders to share their knowledge with the rest of the world. We hope that the Southern Med Review will make a significant contribution to improving the rational use of medicines and access to medicines in developing countries.

Papers should adhere to the Vancouver style convention, and can be 3,500 words maximum. For more information or submitting papers, contact z.babar@auckland.ac.nz

We would like to thank, Pharmacy World and Science, for its support and for providing us with an opportunity to present the Southern Med Review to a global audience. We value that support and hope to meet the expectations of our audience. 